\title{
Catheter-Related Inflammation
}

National Cancer Institute

\section{Source}

National Cancer Institute. Catheter-Related Inflammation. NCI Thesaurus. Code C121604.

Inflammation associated with the use of a catheter. 